\title{
Renal Leiomyoma - A Rare Case Report
}

\author{
Raju Kamlakarao Shinde1, Harsh Dinesh Bhalsod², Sangita Jogdand Shinde ${ }^{3}$
}

1, 2 Department of General Surgery, Jawaharlal Nehru Medical College, Wardha, Maharashtra, India,

${ }^{3}$ Department of Pharmacology, Jawaharlal Nehru Medical College, Wardha, Maharashtra, India.

\section{INTRODUCTION}

Cases of renal leiomyomas are fewer than 100 in the literature and therefore possess a diagnostic challenge. ${ }^{1}$ By definition, leiomyomas are benign soft tissue neoplasms. ${ }^{2}$ that arise from smooth muscle cells. ${ }^{3}$ The most common sites of origin are the uterus, intestines and skin. ${ }^{4}$ One of the more unusual types of leiomyomas are the ones arising from the kidneys. They account for about $1.5 \%$ benign lesions of kidneys. ${ }^{5}$ The methods of detection are through discovery during autopsy, incidental discovery during imaging or by clinical diagnosis in symptomatic lesions. ${ }^{6}$ Prevalence based on incidental finding at the time of autopsy is $4.2-5.2 \% .^{7}$

Creating a differential diagnosis between leiomyomas and other malignant lesions is only possible by histopathological examination. ${ }^{8}$ We hereby report a case of 26-year-old female who presented with pain in abdomen and on histopathological examination was diagnosed as a case of renal leiomyoma.

\section{PRESENTATION OF CASE}

A 26-year-old female presented to Surgery outpatient department with complaints of lump and pain in abdomen since 1 month. Physical examination on admission revealed a palpable mass over right side of the abdomen measuring $15 \times 10 \mathrm{~cm}$, firm, non-tender, ballotable lump. Laboratory investigations such as complete blood count, liver and renal function tests were all within the normal limits. Urine examination was also normal. Computerised Tomography (CT) of the abdomen showed well defined, heterogeneous soft tissue mass arising from upper-mid pole of right kidney measuring 16.4 x $13.8 \times 11.6 \mathrm{~cm}$.

There were multiple necrotic areas within. The lesion was displacing the kidney downwards with indentation over inferior surface of liver, portal vein, aorta, and inferior vena cava. Right radical nephrectomy was carried out.
Corresponding Author: Dr. Harsh Dinesh Bhalsod, Krishna, \# 21, Silver Sand, Street No.1, Opp. Big Bazaar, 150 Feet Ring Road,

Rajkot - 360004,

Gujarat, India.

E-mail: bhalsodharsh94@gmail.com

DOI: $10.14260 / j e m d s / 2021 / 339$

How to Cite This Article:

Shinde RK, Bhalsod HD, Shinde SJ. Renal leiomyoma - a rare case report. J Evolution Med Dent Sci 2021;10(21):1633-1635, DOI: 10.14260/jemds/2021/339

Submission 06-01-2021,

Peer Review 21-03-2021,

Acceptance 27-03-2021,

Published 24-05-2021.

Copyright (C) 2021 Raju Kamlakarao Shinde et al. This is an open access article distributed under Creative Commons Attribution License [Attribution 4.0 International (CC BY 4.0)] 


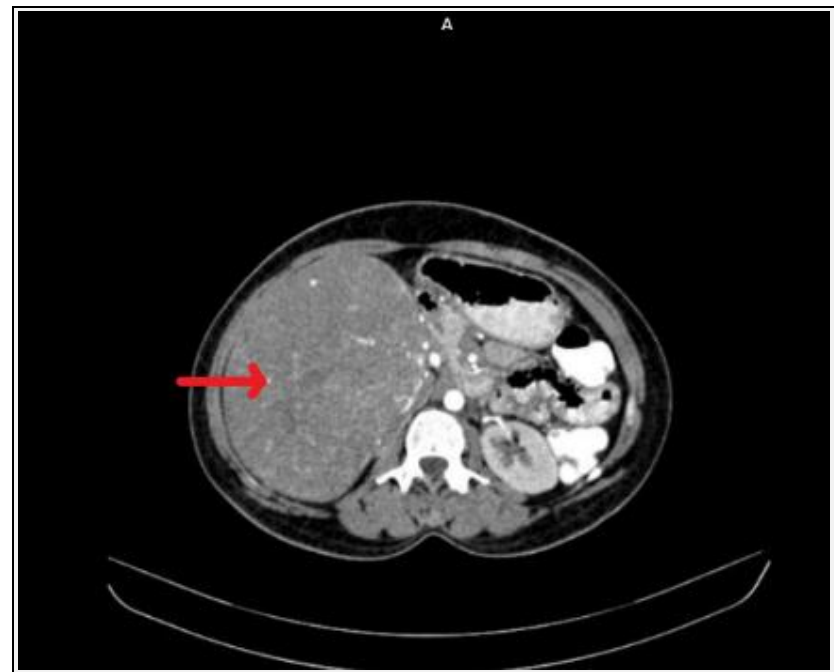

Figure 1. Axial Scan of Contrast Enhanced CT of Right Renal Lesion (Marked Red)

\section{CLINICAL DIAGNOSIS}

Right renal mass

\section{DIFFERENTIAL DIAGNOSIS}

Renal angiomyolipoma

Renal leiomyoma

Renal cell carcinoma

\section{PATHOLOGICAL DISCUSSION}
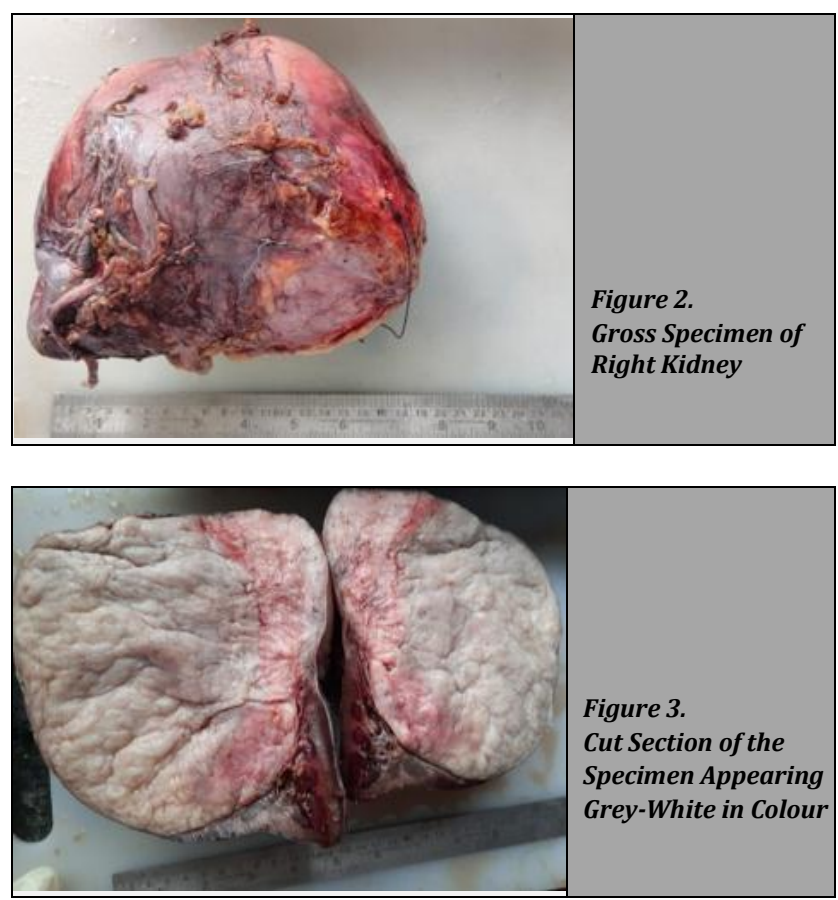

On gross examination, a capsulated renal mass with engorged veins on the surface was identified arising from upper pole measuring $16.5 \times 11.5 \times 10.5 \mathrm{~cm}$. On cut section, the tumour appeared grey white in colour, hard consistency with bulging surface. On microscopic examination, tumour was composed of spindle cells with elongated fusiform nucleus with Scant to moderate cytoplasm.

Multiple collagen bundles noted along with focal areas of fibrosis and dilated. No traits of malignancy like increased nuclear size, nuclear pleomorphism, hyperchromatic changes or prominent nucleoli were seen. Immunohistochemical stains showed that the tumour cells stained positive for SMA and desmin and negative for S - 100 protein, CD34, HMB 45 and Melan-A. This immunohistochemical profile was consistent with the diagnosis of renal leiomyoma.

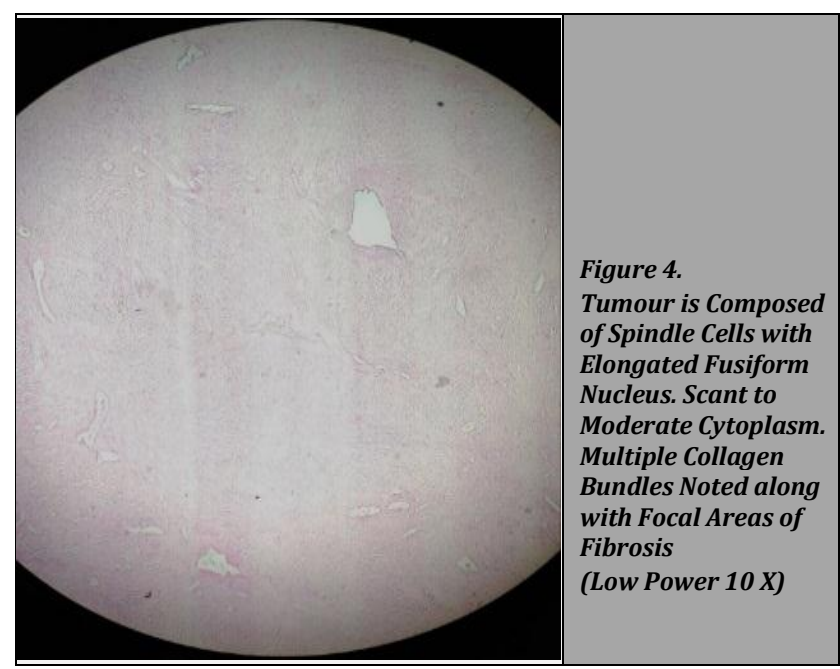

DISCUSSION

Busse was the first to report primary renal leiomyoma and described it ${ }^{5}$ as abundant muscle fibres in embryonic kidney. ${ }^{1}$

Renal leiomyoma may arise from tunica media layer of the renal cortical vessels, smooth muscle cell layer of the renal capsule, or muscularis layer of the renal pelvis.5,9 Accordingly, it is classified into 3 types -

a. Sub capsular lesions (53\%), which are small, multiple and asymptomatic growths usually display necrotic changes

b. Capsular lesions, are mostly large, solitary and symptomatic masses (37 \%);

c. Leiomyoma of the renal pelvis (10\%), rare in nature. ${ }^{1}$

Renal leiomyomas usually remain asymptomatic until they grow large enough to cause symptoms due to mass effect. ${ }^{2}$ The most common symptoms are, palpable lump (57\%) and flank pain (53\%). They have a simultaneous in approximately $33 \%$ of cases. Gross haematuria is only observed in $20 \%$ cases. $^{2}$ Past studies suggest that these tumours show a preponderance towards females.2,1 It may occur in patients ranging from age 6 to 82 years, with the mean age being $47.3,8,9$ Both kidneys show an equal incidence of the tumour, and an approximate of $74 \%$ of the lesions develop in the distal one third of the kidney. ${ }^{1,9}$ But however, in our case, tumour was arising from the upper pole of the kidney.

Incidental diagnosis of renal leiomyoma has increased due to advancements in radiological methods such as ultrasonography and CT. ${ }^{4}$ It exhibits a variety of patterns, ranging from purely cystic to mixed solid and cystic to an entirely solid lesion. ${ }^{4}$ On CT, a sharply demarcated, well- 
defined mass is seen, with no evidence of erosion into the surrounding tissue., 4

On non-contrast study, leiomyoma shows hyperdense attenuation as that of renal parenchyma. On post contrast study the lesion shows less enhancement as that of surrounding parenchyma.5,9 In the larger sized leiomyomas, heterogeneous areas of enhancement can be seen, which occur as a result of haemorrhage, cysts or myxoid degeneration. ${ }^{9}$ In our case, multiple areas of necrosis were seen on the scan.

Macroscopically, renal leiomyoma is described as a solid, well circumscribed, capsulated mass with elastic consistency and whorled surface.5,10 It could be white or red, depending upon vascularization. ${ }^{5,8}$ They can range in size from 0.5 to 57.5 $\mathrm{cm}$ with a mean size of $12.3 \mathrm{~cm} .^{9}$ Tumours $>12 \mathrm{~cm}$ in size may have areas of cystic (17\%) or haemorrhagic degeneration (27 \%). ${ }^{8}$

Microscopically, they appear to be made of fusocellular elements arranged in intersecting fascicles. Characteristics of malignancy such as mitotic figures, pleomorphism, hyperchromatism and perilesional invasivity are all absent.8,9

The main histological differential is angiomyolipoma (AML). ${ }^{7}$ AML is a benign tumour, mesenchymal in origin, constitutes of fat, smooth muscle cells, and abnormally thickwalled blood vessels. ${ }^{3,9}$

In cases of small tumours $<4 \mathrm{~cm}$, conservative surgery may be carried out. However, in large sized leiomyomas, radical nephrectomy is the gold standard treatment. These tumours are usually indolent in nature. They are unlikely to recur, after complete excision. $5,8,9$

\section{FINAL DIAGNOSIS}

Renal leiomyoma.

Financial or other competing interests: None.

Disclosure forms provided by the authors are available with the full text of this article at jemds.com.

\section{REFERENCES}

[1] Mitra B, Debnath S, Pal M, et al. Leiomyoma of kidney: an Indian experience with literature review. Int J Surg Case Rep 2012;3(11):569-73.

[2] Sakai N, Yamada T, Murayama T, et al. Renal leiomyoma: a case report. 1996;42(9):667-9.

[3] Brunocilla E, Pultrone CV, Schiavina R, et al. Renal leiomyoma: case report and literature review. Can Urol Assoc J 2012;6(2):E87-90.

[4] Korgali E, Ayan S, Gökce G, et al. A huge renal mass with uncommon pathology of leiomyoma. Urotoday International Journal 2010;3(4).

[5] Nakib G, Mahgoub N, Calcaterra V, et al. Renal leiomyoma in pediatric age: a rare case report with review of the literature. Journal of Pediatric Surgery Case Reports 2017;27:43-6.

[6] Patil PA, McKenney JK, Trpkov K, et al. Renal leiomyoma: a contemporary multi-institution study of an infrequent and frequently misclassified neoplasm. Am J Surg Pathol 2015;39(3):349-56.

[7] Ajmal A, Jain S. A rare case of renal leiomyoma- case report and literature review. Pathology 2016;48(Suppl 1):S64.

[8] Aldughiman AW, Alzahrani A, Alzahrani T. Renal leiomyoma: case report and literature review. J Endourol Case Rep 2019;5(4):181-3.

[9] Larbcharoensub N, Limprasert V, Pangpunyakulchai D, et al. Renal leiomyoma: a case report and review of the literature. Urol Case Rep 2017;13:3-5.

[10] Filianoti A, Paganelli A, Bassi P, et al. Leiomyoma of the renal capsule: case report and literature review. Urologia 2018;85(1):34-5. 